\title{
BULLYING ESCOLAR: A JUSTIÇA RESTAURATIVA COMO FORMA DE ENFRENTAR E PREVENIR VIOLÊNCIAS
}

http://dx.doi.org/10.5902/2318133816523

\author{
Cristiane Penning Pauli de Menezes \\ Universidade Federal de Santa Maria, Brasil.
}

\section{Daiane Stradiotto Granzzotto}

Universidade de Buenos Aires, Argentina.

\begin{abstract}
Resumo
A interdisciplinaridade entre Direito e Educação permeia o presente artigo ao ligar o tema do bullying com o conceito da Justiça Restaurativa, analisada como um instrumento que pode auxiliar na prevenção dos conflitos que envolvam o bullying no interior das escolas. Assim, o presente artigo tem por objetivo entrelaçar a Justiça Restaurativa aos conflitos de bullying, que atualmente ganham novas roupagens, tendo em vista que as agressões quando não são tratadas com seriedade no ambiente escolar acabam por trazer nas relações interpessoais dos estudantes. Por mais que os debates sobre o tema tenham avançado, novas investigações sobre o tema são imprescindíveis para buscar alternativas de resolução e prevenção destes conflitos, no sentido de preparar os profissionais da comunidade escolar para que possam lidar com esta realidade presente no âmbito escolar.
\end{abstract}

Palavras-chave: bullying, justiça restaurativa, conflitos escolares.

\section{SCHOOL BULLYING: A RESTORATIVE JUSTICE AS FACE OF FORM AND PREVENT VIOLENCE}

\begin{abstract}
The interdisciplinary Law and Education permeates this item to connect the bullying theme, with the concept of Restorative Justice, as analyzed as a tool that can prevent conflicts involving bullying within schools. Thus, this research paper aims to weave Restorative Justice to bullying conflicts, which currently gets new look, considering that the attacks when they are not treated seriously in the school environment just bring reflexes are striking in interpersonal relationships among students. As much as the debates on the subject have advanced, new research on the subject are essential to seek alternative means of resolution and prevention of conflicts, to prepare professionals in the school community.

Key-words: bullying, restorative justice, school conflicts.
\end{abstract}




\section{O bullying no ambiente escolar: os conflitos violentos}

$\mathrm{m}$ dos maiores gargalos que se vislumbra ao tratar da problemática do bullying é identificar quais as condutas, em um ambiente escolar, que podem ser consideradas e qualificas como tal.

Tal consideração é importante tendo em vista que algumas atitudes que deveriam ser enquadradas e percebidas como uma conduta de bullying acabam não sendo percebidas desta forma e, portanto, não são tratadas como uma problema.

Os casos de bullying que são noticiados retratam casos que se utilizam de violência e chamam atenção da mídia, porém, o dia-a-dia da comunidade escolar esconde diversas mazelas causadas por agressores com potencial menor, mas que da mesma maneira causam danos às suas vítimas e precisam de um tratamento reparador.

No ambiente escolar o que ocorrem são conflitos, que são normais no cotidiano e que segundo Carlos Eduardo de Vasconcelos (2008) podem assim ser conceituados:

O conflito não é algo que deva ser encarado negativamente. É impossível uma relação interpessoal plenamente consensual. Cada pessoa é dotada de uma originalidade única, com experiências e circunstâncias existenciais personalíssimas. Por mais afinidade e afeto e afeto que exista em determinada relação algum dissenso, algum conflito, estará presente. ( $p$. 19)

Porém, estes conflitos nem sempre são resolvidos da melhor forma. Diversas vezes a violência é empregada para ampliar os efeitos, o que aumenta as consequências do bullying, que mesmo quando sem violência já deixa rastros em suas vítimas, afetando as relações interpessoais, tendo em vista que as violências não se manifestam apenas em agressões físicas, mas também verbais, morais.

Cléo Fante (2009) atenta para o fato de que o conceito de bullying não é uníssono e, portanto, a falta de rigorosidade no conceito sempre abriu brechas para conceptualizações equivocadas que enquadram-se como preconceito ou discriminação:

Apesar dessa preocupação quanto ao conceito, indivíduos e instituições vêm atribuindo muitas das ações agressivas entre os estudantes, como como bullying, quando na verdade, são atitudes de intolerância, discriminação, preconceito. Como exemplo, podemos citar alguns dos casos veiculados na mídia, onde uma estudante, que por causa do vestido curto que usava, foi discriminada por colegas universitários. Outro caso de uma jovem, que ao chegar à universidade se deparou com os muros pichados, com palavrões que ofendiam a si e a sua mãe. (Fante, 2009, p. 2)

A problemática do bullying manifesta-se em diversos lugares, porém, encontra no ambiente escolar um local propício para disseminação. O maior empecilho encontrado nesta temática, é que o bullying, quando não apresenta violência de forma externada, sendo assim silencioso, apresenta como consequência a constatação de que os profissionais - professores, diretores, pedagogos - negligenciem quanto à identificação da ocorrência do bullying. Nesse sentido Camacho (2007) adverte que

a violência, na sua forma explícita de manifestação nas escolas, é combatida, criticada e controlada por meio de punições. Entretanto, a violência mascarada passa impune, ou porque não é percebida como tal e 
é confundida com a indisciplina, ou porque é considerada pouco grave, isenta de consequências relevantes, ou, finalmente, porque não é vista. Essa violência pode se tornar perigosa porque não é controlada por ninguém, não possui regras ou freios e porque passa a ocorrer constantemente no cotidiano escolar. De tanto acontecer, ela passa a ser banalizada e termina por ser considerada "naturalizada", como se fosse algo "normal", próprio da adolescência. (Camacho, 2007, p. 128)

A forma mais comum de aparecimento do bullying pode ser caracterizada pelos ataques de cunho sexual e racial, representados por agressões de cunho pejorativo que se desenham com intuito de humilhar o agredido frente à turma.

Porém, os ataques não são dirigidos apenas a estas classes, pois atingem etnias, sotaques regionais, obesidade, classe social, modo de vestir, enfim, tudo que fuja da normalidade do grupo agressor.

Assim, não há como descartar o importante papel do educador no que diz respeito à problemática tratada no contexto da presente pesquisa, isto porque os demais estudantes geralmente não identificam uma atitude de bullying e quando identificam, sentem-se amedrontados em enfrentar ou ainda delatar o agressor, isto porque não são preparados para lidar com estas situações que envolvem o bullying.

Cumpre ressaltar que a discriminação trazida pelo bullying ganhou força e assim nasceu a figura o bullying virtual, que é a modalidade facilitada pelo uso da rede virtual - a internet.

A edição de 2014 da pesquisa Este jovem brasileiro, realizada pelo Portal Educacional, revelou que $64 \%$ dos docentes afirmam que percebem casos de ofensas pela internet entre seus alunos e $73 \%$ dizem que estas ofensas geram problemas de relacionamentos entre os colegas (Moreno, 2014).

De outro lado, a pesquisa revelou que $16 \%$ dos alunos relataram ter sofrido insulto ou outra forma de violência na web, $40 \%$ já sentiram-se amedrontados por alguma situação que aconteceu na internet e $4 \%$ admitiram evitar ir à escola ou até sair de casa por ter sofrido ameaças pela web (Moreno, 2014).

Diante desta situação, o papel do educador adquire importância, uma vez que os docentes devem atentar para as práticas repetitivas que vão além de uma simples brincadeira. Segundo Herculano Campos, as brincadeiras repetitivas, quando revestidas da maldade do bullying, resultam em um sentimento de inferioridade diante dos demais colegas (Campos; Cardoso, 2010).

O bullying, quando configurado psicologicamente, possui um caráter agressivo, tendo em vista que se configura por apelidos, ameaças, difamações e fofocas que constrangem o agredido.

Segundo Louzada (2013) o agredido defende-se de seu agressor deixando de ir à escola, alegando para seus genitores que encontram-se acometidos de uma enfermidade, para que dessa forma, tenha um motivo de retirar-se da sala de aula e da escola.

Segundo Louzada (2013) os docentes precisam estar atentos para esta problemática e buscar mecanismos que possam identificar os atores envolvidos no bullying, para que a escola, junto das famílias, elaborem estratégias que propiciem um freio neste mal que acomete o interior das escolas.

E é neste ponto que a justiça restaurativa surge como uma possibilidade interessante. 


\title{
Justiça restaurativa e os procedimentos restaurativos no ambiente escolar
}

É pertinente conceituar a justiça restaurativa, pois, atualmente é considerada uma solução eficiente para solução de conflitos. A justiça restaurativa não é uma nova forma de justiça, apenas está atrelada na busca pelo respeito, igualdade e integridade.

Em conformidade com o disposto por Louzada (2013, p. 69) "a justiça restaurativa cria laços que embasam as relações a fim de diminuir a repetição de novos conflitos". Logo, extrai-se que essa justiça é uma alternativa na solução do bullying no ambiente escolar.

Nesse sentido, percebe-se que ela procura trabalhar a situação conflituosa de maneira harmônica:

\begin{abstract}
A justiça restaurativa baseia-se num procedimento de consenso, em que a vítima e o infrator, e, quando apropriado, outras pessoas ou membros da comunidade afetados pelo crime, como sujeitos centrais, participam coletiva e ativamente na construção de soluções para a cura das feridas, dos traumas e perdas causados pelo crime. Trata-se de um processo estritamente voluntário, relativamente informal, a ter lugar preferencialmente em espaços comunitários, sem o peso e o ritual solene da arquitetura do cenário judiciário, intervindo um ou mais mediadores ou facilitadores, e podendo ser utilizadas técnicas de mediação, conciliação e transação para se alcançar o resultado restaurativo, ou seja, um acordo objetivando suprir as necessidades individuais e coletivas das partes e se lograr a reintegração social da vítima e do infrator. (Pinto, 2005, p. 19)
\end{abstract}

A incidência restaurativa está ligada nos valores da boa conduta social, do respeito ao próximo e se constituirá pela elaboração de acordos e obrigações com vistas a obter a solução pacífica e sem humilhações.

A ideia é restaurar a harmonia no ambiente escolar para que atitudes como o bullying não se tornem hábitos. Assim sendo, a prática da Justiça Restaurativa apresenta dois elementos fundamentais para sua implantação, quais sejam, 1) punir o agressor, para que os demais alunos visualizem a atitude como errônea e desrespeitosa, 2) no entanto, essa punição será pautada no diálogo, não expondo o agressor, o que poderá reverter soluções positivas.

Ainda que existam distintos métodos restaurativos, é indispensável traçar um paralelo entre alguns deles, como o encontro de todos afetados pela situação do conflito, colocando todos na resolução do conflito, objetivando construir em conjunto formas de convivência.

Outro fator importante é a responsabilização dos danos e sua reparação numa preocupação concomitante de restauração da relação antes dos danos a serem causados, mas, também, de equacionamento projetivo desta relação para evitar nova emergência do conflito.

Com a adoção dos procedimentos da justiça restaurativa o bulliyng poderá ser observado sob outra ótica, pois a busca para solução dos conflitos parte das instituições que, entre si, participam da implementação de um novo paradigma de ação, articulado e comprometido com o envolvimento participativo de todos:

A justiça restaurativa é um campo em expansão para atuar no desenvolvimento de modelos relacionados às políticas públicas da infância e da juventude; com ênfase no Estatuto da Criança e do Adolescente que 
visa ao atendimento integrado do adolescente no Sistema de Justiça e as escolas têm criado espaços para o exercício desta prática dialógica e emancipatória na concepção de uma educação não mais voltada somente para o conteúdo, mas uma educação voltada para a cidadania, para a ressignificação de práticas e saberes docentes. (Grossi et al., 2009, p. 502).

Assim, cumpre ressaltar que é necessário um conjunto de ações a fim de garantir a efetivação da educação. E para que o fim da prática do bullying se concretize é fundamental a participação do Estado, da família e da comunidade escolar.

A participação da família, do Estado e da escola é essencial para a internalização da justiça restaurativa nas políticas públicas educacionais e surtindo seus almejados efeitos na solução dos conflitos.

Este processo restaurativo, com a participação de todos envolvidos, traz para a escola uma metodologia positiva de lidar com os problemas e proporcionará uma educação baseada nos pilares do respeito, da dignidade da pessoa humana, fortalecendo o diálogo, o bem estar e a convivência harmônica:

As praticas restaurativas na escola ajudam a desenvolver um conjunto de valores e habilidades baseadas no respeito, na igualdade e na dignidade de todas as pessoas [...] desenvolvem no individuo pensamento crítico, as habilidades para solucionar problemas, as assertivas e a empatia pelo outro. (Nunes, 2011, p. 10)

Assim, a justiça restaurativa no ambiente escolar, que não pode ser confundida com a normatização aplicada no Poder Judiciário, mesmo possuindo alguns elementos em comum, possui um conjunto de valores essenciais para solução dos conflitos pela prática do bullying, pois sua aplicação possui a intenção de punir e prevenir essa prática nas escolas.

\section{Considerações finais}

A prática do bullying nas escolas configura uma problemática atual e emergente, que precisa ser trabalhada de forma preventiva e restaurativa. Deste modo, compreende-se que a justiça restaurativa é um modelo na resolução dos conflitos, que pode ser bem aproveitado para resolução de conflitos advindos de atos de bullying escolar, tendo em vista que trata-se de um processo colaborativo que envolve todos os afetados direta ou indiretamente.

Frequentemente, o noticiário relata casos em que o bullying traz graves consequências, e é importante saber que muitos destes casos iniciam com uma mera brincadeira que por muitas vezes não foi identificada pelos educadores como uma prática de bullying e tornam-se insustentáveis.

Sabe-se que a pratica do bullying sempre existiu e é comum nas escolas nos seus mais variados níveis, contudo, este tema ganhou forças e esta sendo palco de diversas discussões. Uma das soluções encontradas é a justiça restaurativa, que permite que se discutam as causas das manifestações de violência e as relações envolvidas no conflito, buscando o restabelecimento do respeito e da convivência harmônica entre os envolvidos. 
No entanto, para que as políticas envolvendo a justiça restaurativa ganhem forças e sejam aplicadas na sua integralidade no âmbito escolar, elas precisam do apoio do Estado, da família e de toda comunidade escolar, porque assim se estará tratando o problema de forma global e não apenas dentro da esfera escolar.

\section{Referências}

CAMACHO, Luiza Mitiko Yshiguro. As sutilezas das faces da violência nas práticas escolares de adolescentes. Educação e Pesquisa, São Paulo, v. 27, n. 1, 2001, p. 123140. Disponível em <http://www.scielo.br/pdf/ep/v27n1/a09v27n1.pdf >. Acesso em 15 nov. 2014.

CAMPOS, Herculano Ricardo; CARDOSO, Samia Dayana Jorge. Violência na escola: uma reflexão sobre o bullying e a prática educativa. Em Aberto, Brasília, v. 23, n. 83, 2010, p. 107-128.

FANTE, Cléo. Bullying no ambiente escolar. Disponível em < http://inov.org.br/site/ artigos/9.pdf>. Acesso em 15 nov. 2014.

LORENZONI, Nelnie Viali. Manual pedagógico das práticas restaurativas. Porto Alegre: SEC, 2010.

LOUZADA, Marcelle Cardoso. Os conflitos violentos de bullying na escola e seus entrelaçamentos com a justiça restaurativa. Santa Maria: UFSM. 2013.

MORENO, Ana Carolina. 64\% dos professores relatam bullyng entre alunos na internet, diz pesquisa. Disponível em http://g1.globo.com/educacao/noticia/2014/08/64-deprofessores-relatam-bullying-entre-alunos-na-internet-diz-pesquisa.html. Acesso em 15 nov. 2014.

NUNES, Antonio Ozório. Como restaurar a paz nas escolas: um guia para educadores. São Paulo: Contexto, 2011.

GROSSI, Patrícia Krieger; SANTOS, Andréia Mendes dos; OLIVEIRA, Simone Barros de; FABIS, Camila da Silva. Implementando práticas restaurativas nas escolas brasileiras como estratégia para a construção de uma cultura de paz. Rev. Diálogo Educ., Curitiba, v. 9, n. 28, 2009, p. 497-510.

PINTO, Renato Sócrates Gomes. Justiça restaurativa é possível no Brasil? In: SLAKMON, Catherine; VITTO, Renato Campos Pinto (org.). Justiça restaurativa. Brasília: Ministério da Justiça; Programa das Nações para o Desenvolvimento - PNUD, 2005.

VASCONCELLOS, Carlos Eduardo de. Mediação de conflitos e práticas restaurativas. São Paulo: Método, 2008.

Cristiane Penning Pauli de Menezes é estudante no curso de mestrado em Direito da Universidade Federal de Santa Maria, com ênfase em Direitos Emergentes na Sociedade Global, linha de Pesquisa Direitos da Sociobiodiversidade e Sustentabilidade.

Endereço postal completo: Rua Duque de Caxias, 1181 - 97015-190 - Santa Maria RS - Brasil.

E-mail: cristiane@bptadvogados.adv.br. 
Daiane Stradiotto Granzzotto é estudante no curso de doutorado em Direito na Universidade de Buenos Aires.

Endereço: Rua Linha Duas, s/n - 97195-000 - Silveira Martins - RS - Brasil.

E-mail: daiasg@yahoo.com.br.

Recebido em 18 de dezembro de 2014.

Aceito em 7 de abril de 2015. 